\title{
A VUELTAS CON LA REFORMA CONSTITUCIONAL DEL SENADO: DE LAS OPCIONES A LAS DECISIONES
}

\author{
PIEDAD GARCÍA-ESCUDERO MÁRQUEZ \\ Letrado de las Cortes Generales \\ Profesora Titular de Derecho Constitucional \\ Universidad Complutense de Madrid
}

\section{SUMARIO}

I. La representación territorial del Senado. De la reforma reglamentaria a la reforma constitucional.

II. La composición del Senado.

III. Las funciones del Senado.

IV. Aspectos relevantes del funcionamiento del Senado.

V. Observación final.

\section{LA REPRESENTACIÓN TERRITORIAL DEL SENADO. DE LA REFORMA REGLAMENTARIA A LA REFORMA CONSTITUCIONAL}

Puede decirse que desde los primeros tiempos postconstitucionales y, más acusadamente, a partir del décimo aniversario de la Constitución, se convirtió en lugar común hablar de la reforma del Senado, de la incapacidad de la segunda Cámara para cumplir la función que le atribuye el artículo 69 de la Carta Magna al declarar que "el Senado es la Cámara de representación territorial»".

1 Véase, sobre la cláusula calificatoria del Senado como territorial, dimensión que no afectaría tanto a la base u origen del Senado - la procedencia de sus miembros- como al señalamiento de su función fundamental, realizar la representación territorial (pág. 90), J. J. SOLOZÁBAL ECHAVARRÍA, "Alcance jurídico de las cláusulas definitorias constitucionales (A propósito de la calificación del Senado como Cámara de representación territorial)", Revista española de Derecho Constitucional, n. ${ }^{\circ} 15,1985$, págs. 79 y ss. 
A una primera etapa de lamentación, sucedió una de limitada acción: de las dos vías posibles para su reforma, reglamentaria o constitucional, se optó en un primer momento por la primera, que, abordada desde la III legislatura, culminó con la aprobación de la reforma del Reglamento del Senado de 11 de enero de 1994. La reforma, orientada a "potenciar la función territorial del Senado", se centró básicamente ${ }^{2}$ en la creación de una Comisión General de las Comunidades Autónomas, de carácter legislativo, pero a la que se atribuye un listado de hasta veintitrés otras funciones (art. 56 RS), fundamentalmente de recibir información y emitir dictamen sobre cuantos asuntos de "naturaleza autonómica" o "Contenido autonómico" haya de conocer el Senado: convenios entre Comunidades Autónomas, autorización prevista en el artículo 155 de la Constitución, proyectos de ley de transferencia o delegación a las Comunidades Autónomas, proyectos de ley de armonización, etc. En definitiva, se quiso dar participación a la Comisión General en las iniciativas de matiz territorial, por cuanto en ella pueden intervenir los representantes de los Consejos de gobierno de las Comunidades Autónomas, tímido inicio de la participación de éstas en la Cámara Alta. Asimismo pueden hacer uso de la palabra en la Comisión los senadores designados por las Asambleas autonómicas en aplicación del artículo 69.5 de la Constitución.

De las funciones atribuidas a la Comisión General, destacaremos la facultad de iniciativa legislativa mediante la presentación de proposiciones de ley [art. 56.s) RS], la posibilidad de informar sobre el contenido autonómico de cualquier iniciativa que haya de ser tramitada en el Senado [art. 56.b)], en particular sobre los proyectos y proposiciones de ley antes de que concluya el plazo de enmiendas, y las facultades de informe y seguimiento sobre la distribución del Fondo de Compensación Interterritorial [art. 56. ̃)].

Para hacerse una idea de la escasa efectividad de esta reforma reglamentaria, basta con tres datos o indicios, reveladores del escaso entusiasmo (léase voluntad política) con que la acogieron sus propios autores: en diez años, la Comisión General de las Comunidades Autónomas (estrella de la reforma) ha emitido informe sobre el contenido autonómico de seis textos le-

2 Además de la modificación simbólica consistente en incorporar a los debates de la Cámara Alta las lenguas que tengan, junto con el castellano, carácter oficial en alguna Comunidad Autónoma, en dos ocasiones: en la sesión constitutiva, el Presidente puede utilizarlas en su primera intervención ante el Pleno, con contenido idéntico en las diferentes lenguas (art. 11 bis RS); en la Comisión General de las Comunidades Autónomas, en el debate anual sobre el Estado de las Autonomías (art. 56 bis 7.2). Este apartado es suprimido por la reciente reforma del Reglamento del Senado, de 4 de julio de 2005 (BOE n. ${ }^{\circ}$ 159, de 5 de julio), que amplía la utilización de estas lenguas a todas las intervenciones que se produzcan en las sesiones de la Comisión General de las Comunidades Autónomas, reproduciéndose íntegramente en el Diario de sesiones en la lengua en que se hayan realizado [56 bis 9 (nuevo) RS].

Asimismo, los ciudadanos y las instituciones podrán dirigirse al Senado en cualquiera de las lenguas cooficiales en alguna Comunidad Autónoma, facilitando la Cámara su traducción para la tramitación correspondiente (disposición adicional cuarta RS). Desde la última reforma citada, si el autor de una moción, interpelación o pregunta la presenta en castellano y además en una de las lenguas oficiales, la iniciativa se publicará también en esa lengua [191.2 (nuevo) RS]. 
gislativos $^{3}$; nunca ha ejercido la iniciativa legislativa; en cuanto al debate sobre el estado de las autonomías, previsto con carácter anual, ha tenido lugar en dos ocasiones (1994 y 1997).

La reforma reglamentaria no terminó con las aspiraciones de modificación constitucional de la Cámara Alta, para cuyo estudio continuó funcionando en las legislaturas V, VI y VII una ponencia de estudio. Al mismo tiempo, la doctrina ha ido apuntando, en una bibliografía que cabría calificar ya de abundante, las soluciones teóricas posibles a la reforma constitucional planteada. Puede decirse que, desde el punto de vista teórico está casi todo dicho, a la espera de que las decisiones de los actores políticos vayan marcando el camino por donde profundizar.

En la VIII legislatura, la reforma del Senado constituye uno de los cuatro puntos de la reforma constitucional anunciada por el Presidente del Gobierno en la exposición de su programa de gobierno, en la sesión de investidura. La reciente consulta del Gobierno al Consejo de Estado, que puede decirse supone el pistoletazo de salida de la reforma constitucional, no aporta ninguna pista sobre la dirección en que se desarrollaría aquélla, limitándose a preguntar por las funciones que debe ejercer el Senado como Cámara de representación territorial (es-

3 En la V legislatura, sobre el Proyecto de Ley de reforma de la Ley Orgánica del Poder Judicial y el Proyecto de Ley de declaración del Parque Nacional de los Picos de Europa; sobre los Proyectos de Ley de Presupuestos Generales del Estado para 1997 y 1999 y el Proyecto de Ley de Medidas que acompañaba al primero, en la VI legislatura, y un informe en la VII, sobre la Proposición de ley básica reguladora de la autonomía del paciente y de derechos y obligaciones en materia de información y documentación clínica. Las cifras se explican por sí solas.

A comienzos de la VI legislatura, la Comisión General delegó con carácter genérico a favor de la Mesa, reunida conjuntamente con los portavoces de los grupos parlamentarios, para el ejercicio de las competencias en materia de informe sobre el contenido autonómico de las iniciativas, aunque con el deseo de que fuera sólo una delegación cautelar en previsión de situaciones de urgencia (véase A. DORREGO DE CARLOS y C. GUTIÉRREZ VICÉN, "El Senado”, en Informe Comunidades Autónomas 1996, vol. I, Instituto de Derecho Público, Barcelona, 1997, págs. 83 y ss.) y que finalmente fue utilizada para los informes sobre el contenido autonómico de tres proyectos que acompañaban al Proyecto de Ley de Presupuestos para 1997 (Proyecto de Ley Orgánica de modificación de la LOFCA y Proyectos de Ley de cesión de tributos del Estado a las Comunidades Autónomas y de medidas de disciplina presupuestaria), debatiendo la Comisión los informes sobre el contenido autonómico del citado Proyecto de Ley de Presupuestos y del Proyecto de Ley de medidas fiscales, administrativas y del orden social. En años posteriores, además de los informes citados en esta nota, algunos otros fueron asimismo tramitados por la Mesa y los portavoces de la Comisión General. C. GUTIÉRREZ VICÉN ("El Senado", en Informe Comunidades Autónomas 1998, Instituto de Derecho Público, Barcelona, 1999, pág. 94) da cuenta de la tramitación del informe sobre el Proyecto de Ley de Presupuestos Generales del Estado para 1999, señalando que se mantenía la tendencia, iniciada en 1996, de abandonar la técnica de elaboración y presentación del informe ante la Comisión General por un relator miembro de la misma. El sistema consolidado implica el debate, en el seno de la Comisión, de informes estrictamente técnicos (véase, por ejemplo, el Diario de sesiones de la CGCA n. ${ }^{\circ}$ 69, de 28 de noviembre de 1996, pág. 55), de forma que el contenido político se incorpora al mismo en las intervenciones efectuadas por distintos grupos parlamentarios. De este modo, el informe se remite a la Comisión legislativa de que se trate acompañado del correspondiente Diario de sesiones. Así se hizo también en este caso, en el que no acudió ningún representante autonómico, enviándose el informe a la Comisión de Presupuestos. (Véase Diario de sesiones de la CGCA n. ${ }^{\circ}$ 372, de 30 de noviembre de 1998, págs. 2, 6 y 12). 
pecificando algunas en particular), la composición más adecuada, la posición institucional del Senado en el seno de las Cortes Generales y las consecuencias sistemáticas que comportaría en el conjunto de la estructura constitucional.

No es propósito de estas líneas el tratar de realizar aportaciones originales. Intentaré solamente sistematizar las cuestiones planteadas, con indicación de algunas opciones posibles, entre las que podrían oscilar las decisiones que, necesariamente, han de ser adoptadas si se desea que la reforma constitucional llegue a ser cuando menos un proyecto. La consulta del Gobierno al Consejo de Estado plantea primero (probablemente de forma deliberada) las funciones que debe ejercer el Senado como Cámara territorial y después la composición más adecuada para ejercer esas funciones ${ }^{4}$, pero creo que el orden de debate puede ser perfectamente el inverso, puesto que la composición puede determinar la naturaleza de la Cámara y, por tanto, sus competencias y su posición institucional en el seno de las Cortes Generales.

El punto de partida ha de ser, obviamente, el papel del Senado en un Estado sui generis como es el autonómico. Se le reprocha que, al duplicar en su elección la circunscripción provincial del Congreso, no tiene en cuenta la verdadera representación territorial, que debería ser la de las Comunidades Autónomas. Desde los primeros momentos de vigencia de la Constitución se dijo que, al regular la composición del Senado, ésta había nacido provisional, ya que no era posible que con las Comunidades Autónomas en funcionamiento pudiera seguir manteniéndose el criterio de la representación provincial ${ }^{5}$. En el momento actual, no se cuestiona que el nuevo Senado debe ser la Cámara de las Comunidades Autónomas 6 , y que esa "representación territorial" deberá derivar tanto de su forma de elección como de las funciones que ejerza.

En estos dos aspectos nos vamos a centrar a continuación. No se oculta, no obstante, que las implicaciones de la reforma del Senado podrían ir más allá del aspecto orgánico (por mucho que se trate de un órgano constitucional) para llegar a afectar (tangencialmente o de lleno, según quede delimitada la reforma) a

4 Éste es también el orden de examen que sigue E. AJA en El Estado autonómico. Federalismo y bechos diferenciales, 2. ${ }^{a}$ ed., Alianza Editorial, Madrid, 2003, págs. 247 y ss., aunque no en las conclusiones, págs. 339 y ss.

5 E. RECODER DE CASSO, "Comentario al artículo 69", en Comentarios a la Constitución, dirigidos por F. Garrido Falla, Civitas, Madrid, 1980, pág. 735. No obstante, ha de recordarse brevemente la existencia de elementos territoriales en la composición del Senado, en particular ese veinte por ciento de composición de la Cámara que son los llamados senadores autonómicos (véase P. GARCÍA-ESCUDERO MÁRQUEZ, Los Senadores designados por las Comunidades Autónomas, Cortes Generales-CEC, Madrid, 1995), además de la sobrerrepresentación de las islas y de Ceuta y Melilla, así como, finalmente, la posibilidad de compatibilizar el mandato de senador con el de diputado autonómico que permite el art. 67.2, posibilidad vedada a los diputados. Luego volveremos sobre este tema al reflexionar sobre la eventual composición de un nuevo Senado.

6 Dice I. MOLAS i BATLLORI ("Sobre la reforma del Senado", en Veinticinco años del Senado: 1977-2002, Senado, Madrid, 2004, págs. 177-179) que la Constitución española configuró el Senado antes de que existiera materialmente el Estado de las Autonomías, siendo necesario que pueda realizar su función específica de representación territorial en las circunstancias actuales, expresando la organización territorial del Estado realmente existente. 
la estructuración territorial del Estado configurada por los constituyentes en un equilibrio entonces consensuado, plasmado en el artículo $2 .^{\circ}$ y en el Título VIII de la Carta Magna. Éstas y no otras son las razones de que se aborde aquélla con tanta cautela, mayor a medida que aparecen nuevos elementos que complican la posibilidad de llegar a acuerdos.

\section{LA COMPOSICIÓN DEL SENADO}

\section{A) OpCiONES BÁSICAS}

Haciendo abstracción de las circunstancias actuales, cabría situar a nuestro Senado en la corriente renovadora de las segundas Cámaras. Dos caminos podrían abrírsele, desde este punto de vista: su democratización o su territorialización. La democratización, en nuestro caso, convertiría al Senado aún más en una duplicación de la composición del Congreso de los Diputados, si se pasara del sistema electoral mayoritario a un sistema proporcional. La territorialización, en cambio, es la que se plantea como objetivo en todas las peticiones de reforma. ¿Cuáles son las posibilidades que se ofrecen? Las fórmulas que se barajan en el debate se contraen a las que aporta el Derecho comparado: que los miembros del Senado sean elegidos por la población de las Comunidades Autónomas, siguiendo por analogía el ejemplo de Estados Unidos y Suiza; por los Parlamentos de aquéllas, lo que supondría elevar los Senadores del artículo 69.5 de la Constitución a la composición total de la Cámara (a su vez, en esta opción, cabe inclinarse por un sistema de elección mayoritario o, como el que actualmente impone la Constitución, proporcional); y finalmente, la designación por los Gobiernos autonómicos, siguiendo el modelo del Bundesrat alemán.

\section{1) Modelo Bundesrat}

Esta última fórmula podría considerarse excesivamente ajena a nuestra vida política como para que una reforma constitucional se atreviera a experi-

7 Fórmula mixta sería la propuesta por E. AJA en «El Senado autonómico, entre la reforma reglamentaria y la reforma constitucional", en Informe Comunidades Autónomas 1993, Instituto de Derecho Público, Barcelona, 1994, vol. I, págs. 575 y ss.), que incluye representación de la mayoría en el Parlamento y Gobierno autonómicos así como de los grupos parlamentarios de la oposición. Cierta similitud con esta propuesta guarda la de M. MARTÍNEZ SOSPEDRA, quien, además de proponer el aumento del número de senadores designados sin necesidad de reforma constitucional, interpretando el artículo 69.5 de forma que las fracciones inferiores al millón de habitantes proporcionen un senador adicional, aboga por un método y un instrumento normativo comunes para la elección de los senadores autonómicos (que deberían ser diputados autonómicos y al menos uno de ellos miembro del Gobierno autonómico) (La reforma del Senado, Fundación Universitaria San Pablo CEU, Valencia, 1990, págs. 197198). También J. M. a GIL-ROBLES ("El Senado en la Constitución española", en Tapia, n. ${ }^{\circ} 43$, 1988, pág. 30) se plantea la posibilidad de combinar senadores elegidos por los Parlamentos y por los Gobiernos autonómicos. 
mentar con ella. No han faltado, sin embargo, ciertas opiniones favorables: Santaolalla entiende que fomentaría una mayor responsabilidad de los Gobiernos autonómicos en la política general del Estado y suscitaría actitudes más solidarias ${ }^{8}$. En el mismo sentido, BouzaBrey opina que esta opción sería la más adecuada a las necesidades de desarrollo del Estado autonómico?, e igualmente desde un primer momento Trujillo, por evitar la división del voto de la representación del territorio autónomo y favorecer la función coordinadora de la Administración estatal descentralizada y la política territorial autonómica ${ }^{10}$.

Pero incluso los propios autores que declaran inclinarse, en el ámbito teórico, por esta solución, reconocen las dificultades para su puesta en práctica y proponen finalmente otra opción. Así, Aja alega como ventaja del sistema alemán la eficacia en la representación de la posición de los Gobiernos de los Länder, y como desventaja el que el Bundesrat no constituye una Cámara parlamentaria, sino una especie de "Dieta" que representa a los Gobiernos, lo que podría cuestionar el carácter jurídicoconstitucional de las Cortes y la propia declaración del artículo 66.1 de la Constitución ${ }^{11}$. Asimismo, Torres Del Moral cree difícil que la opinión pública, a quien ya cuesta trabajo aceptar la disciplina de voto de los partidos o de los grupos parlamentarios, no viera en el mandato imperativo de los Gobiernos autonómicos sobre sus senadores una liquidación del Parlamento e incluso una disolución del Estado en las Comunidades Autónomas ${ }^{12}$. Fernández Segado, por su parte, considera que la

8 F. SANTAOlalla, El Parlamento en la encrucijada, Eudema, Madrid, 1989, pág. 82.

9 L. BOUZA-BREY, "Hipótesis para una reforma del Senado", en Autonomies. Revista Catalana de Derecho Público, n. ${ }^{\circ}$ 6, 1987, pág. 62. También X. ARBÓs, "El Senado: marco constitucional y propuestas de reforma", en Revista de las Cortes Generales, n. ${ }^{\circ} 24,1991$, se inclina por el modelo Bundesrat, aunque reconoce que habría que resolver problemas como el criterio igualitario o no para la representación de las Comunidades Autónomas, siendo partidario de la segunda solución.

10 G. TRUJILLO, "La regionalización del Estado", en Estudios sobre el proyecto de la Constitución, CEC, Madrid, 1978, pág. 520.

11 E. AJA, "Perspectivas de la reforma constitucional del Senado", en La reforma del Senado, Senado-CEC, Madrid, 1994, págs. 220-221. Proponía como número de senadores, en caso de optarse por esta solución, el actual del artículo 69.5. Más recientemente ("De los Gobiernos autonómicos", El País, 2 de mayo de 2004), AJA insiste en que sería más fuerte el Senado integrado por miembros de los Gobiernos autonómicos "porque éstos se han convertido en los auténticos pilares de las respectivas Comunidades Autónomas". También M. HERRERO DE MIÑÓN ("Para la reforma del Senado", El País, 27 de mayo de 2004), entendiendo que "los gobiernos son, por regla general, menos partidistas que las Asambleas". Su ponderación de voto parece tendría en cuenta factores distintos de la población, en suma, los llamados hechos diferenciales.

12 A. TORRES DEL MORAL, "El Senado", en Revista de Derecho Político, n. 36 (La reforma constitucional), 1992, pág. 362. G. TRUJILLO llamaba la atención sobre el hecho de que, aunque los elementos de caracterización cercana a un paradigma de tipo federal que ofrece la Constitución están clarísimamente orientados hacia una segunda Cámara de tipo Senado, más que de tipo Consejo, paradójicamente se vuelven los ojos una y otra vez al Bundesrat alemán y no a otros tipos de segundas Cámaras territoriales ("Intervención en el debate sobre la reforma del Senado", Asamblea regional de Murcia, en Anuario de Derecho Constitucional y Parlamentario, n. ${ }^{\circ}$ 3, 1991, pág. 192). Según R. BLANCO VALDÉS ("La reforma del Senado", Claves de razón práctica, n. 이, 2005, pág. 44), se correría el riesgo con este tipo de Senado de que acabara convirtiéndose, antes o después, en un disfuncional contrapoder, no sólo del Congreso, sino sobre todo del Gobierno del Estado. 
opción Bundesrat no es encuadrable en la forma de Estado regional constitucionalizado en nuestro país ${ }^{13}$.

Tal vez del conjunto de los argumentos expresados destaque el que mirar hacia el modelo Bundesrat al configurar el futuro Senado sería una especie de vuelta atrás desde una Cámara democrática que forma parte de nuestra reciente tradición constitucional. Tampoco cabe desconocer que la fórmula Bundesrat se cuestiona en la actualidad incluso en la propia Alemania. Para evitar el predominio de los partidos políticos en el Bundesrat, que le priva de su sentido original de Cámara de los Länder, se levantan voces a favor de su reforma hacia un modelo Senado, o para variar sus funciones o el procedimiento de adopción de acuerdos ${ }^{14}$.

\section{2) Elección en circunscripción autonómica}

Las soluciones factibles en la práctica quedarían, si se abandonara el modelo Bundesrat, circunscritas a dos.

Primera, la elección directa en circunscripción coincidente con la Comunidad Autónoma. Se manifiesta a favor de la elección directa con circunscrip-

13 F. FERNÁNDEZ SEGADO, "El bicameralismo y la naturaleza del Senado", Revista Española de Derecho Constitucional, n. ${ }^{\circ}$ 6, 1982, pág. 111. En otro lugar ("La funcionalidad del Senado en cuanto Cámara de representación territorial", en Revista Vasca de Administración Pública, n. ${ }^{\circ} 13$, 1985, pág. 449), se refiere a una fórmula oficiosa estudiada en tiempos por el Gobierno para aproximarse al modelo alemán, consiguiendo que al menos uno de los senadores designados por cada Comunidad formara parte del Ejecutivo de la misma. Estos senadores se integrarían en la entonces Comisión de Autonomías. Este proyecto, que el autor califica de especialmente atractivo, toparía con la autonomía organizativa de las Comunidades Autónomas. También A. SÁIZ ARNAIZ piensa que el modelo de Bundesrat podría, en hipótesis, incidir sustancialmente en la forma de gobierno, además de obligar a una revisión en profundidad del Título III de la Constitución. Estos motivos, y la ausencia de argumentos que, más allá del ejemplo alemán, jueguen a su favor, le llevan a descartar este modelo para el futuro Senado ("El Senado y las Comunidades Autónomas", en Revista Vasca de Administración Pública, n. ${ }^{\circ} 41,1995$, págs. 316-317).

14 Véase G. STROHMEIER; “Der Bundesrat: Vertretung der Länder oder instrument der Parteien?", Zeitschrift für Parlamentsfragen, n. ${ }^{\circ}$ 4, 2004, págs. 717 y ss., en particular págs. 730-731. Obviamente, no se trata (porque sería imposible) de conseguir una Cámara que filtrara los intereses de los partidos políticos y sólo representara a los Länder. Pero se aboga por que la reforma del federalismo transfiriera determinadas competencias del nivel federal al nivel Länder, residenciándolas así en sus parlamentos; de esta forma aumentarían las competencias de éstos y disminuiría la del Bundesrat. Pero las mayorías requeridas hacen improbable una reforma en este sentido, precisamente por la politización del Bundesrat. Véase también un interesante estudio y resumen de las propuestas doctrinales para evitar las mayorías contrapuestas, en V. WAGSCHAL y M. GRASL, "Die modifizierte Senatslösung. Ein Vorsschlag zur Verringerung von Reformblockaden im deutschen Föderalismus", Zeitschrift für Parlamentsfragen, n. ${ }^{\circ}$ 4, 2004, págs. 732 y ss. Entre nosotros, el propio Aja reconoce que, por el "peligro de parálisis, e incluso por circunstancias quizá incluso más difíciles, la fórmula de un Senado integrado por Gobiernos supone retos más difíciles que un Senado de carácter parlamentario", pero que "en cambio, las posibilidades de integración y eficacia son infinitamente superiores si se forma a partir de los gobiernos autonómicos" (El Estado autonómico. Federalismo y hechos diferenciales, cit., pág. 265). 
ción autonómica Fernández Segado ${ }^{15}$, quien plantea también la posibilidad de que el sistema electoral fuera el mayoritario mediante colegios uninominales, aun reconociendo el peligro de que el senador así elegido representara, más que a la Comunidad, al distrito uninominal en que ha sido votado ${ }^{16}$. López Garrido se ha inclinado también por la circunscripción autonómica, en la que se elegiría un Senado de 180 miembros $^{17}$, e igualmente los Presidentes de diez Parlamentos autonómicos, en una reunión celebrada el 25 de noviembre de 1994, que además señalaron — - según informó la prensa- la necesidad de simultanear las elecciones al Senado con las autonómicas y de unificar los mandatos de los senadores, pero descartando la acumulación de mandatos.

Ahora bien: las propuestas que tienden a sustituir la provincia por la Comunidad Autónoma como circunscripción electoral tienen un sentido limitado $y$, posiblemente, no tan trascendente como se piensa: en definitiva, ser elegido por una circunscripción que abarque todo el territorio de una Comunidad no convierte al senador en representante directo de aquélla y no supone un correctivo radical, como a veces se afirma, al predominio de los partidos en la vida política y parlamentaria. Ello por una razón muy simple: que también en las Comunidades Autónomas juega, como es obvio, la tendencia homogeneizadora que suponen los grandes partidos de implantación nacional; incluso si por esta vía se vieran superados en las elecciones los partidos nacionales por partidos nacionalistas o regionalistas de fuerte arraigo en una Comunidad determinada, los intereses de éstos no podrían identificarse sin más con los de la Comunidad como institución jurídico-política ${ }^{18}$.

15 F. FERNÁNDEZ SEGADO, "El bicameralismo y la naturaleza del Senado", cit., pág. 111.

16 No obstante, en su comparecencia como experto ante la Ponencia de reforma del Senado, revisó esta postura, por razones posibilistas, proponiendo el mantenimiento del actual sistema mixto de elección, reajustando el número de senadores a elegir por circunscripción provincial y por cada Comunidad Autónoma. Véase también F. FERNÁNDEZ SEGADO, «Reflexiones en torno a la reforma constitucional del Senado", en A. PÉREZ CALVO (coord.), La participación de las Comunidades Autónomas en las decisiones del Estado, Tecnos, Instituto Navarro de Administración Pública, Madrid, 1997, págs. 197-200.

17 Cinco Senadores por circunscripción electoral más uno por cada 500.000 habitantes o fracción superior a 250.000, coincidiendo las elecciones con las de las Asambleas legislativas de las Comunidades Autónomas (D. LÓPEZ GARRIDO, "Hacia un nuevo Senado. Propuesta de reforma constitucional", en Revista de las Cortes Generales, n. ${ }^{\circ} 33$, 1994, págs. 7 y ss.).

18 En el mismo sentido, L. LÓPEZ GUERRA considera que la conversión de las Comunidades Autónomas en circunscripciones electorales no representaría un cambio apreciable respecto de la situación actual; quizá alteraría la representación partidista, "pero no se ve cómo podría afectar o promocionar la representación de los intereses "propios" de cada Comunidad Autónoma" "Algunas notas sobre la igualación competencial", en Documentación Administrativa, núms. 232-233, 19921993, pág. 133). Por su parte, J. A. PORTERO MOLINA ( Reflexiones sobre algunas propuestas de reforma constitucional del Senado", en A. Pérez Calvo (coord.), La participación de las Comunidades Autónomas en las decisiones del Senado, Tecnos, Madrid, 1997, pág. 230) entiende que lo que explica el comportamiento electoral no es el tamaño de la circunscripción, sino la naturaleza de las elecciones. Véase también V. FRANCH I FERRER y J. MARTÍN CUBAS, "Reflexiones en torno a una posible reforma del sistema de asignación de escaños en el Senado", en Cuadernos Constitucionales de la Cátedra Fabrique Furió Ceriol, n. ${ }^{\text {os }}$ 18/19, Valencia, 1997, págs. 36-37. 


\section{3) Elección por los Parlamentos autonómicos}

La última opción consiste en la elección por los Parlamentos autonómicos, por un sistema mayoritario o proporcional, opción que, merced a la existencia de los actuales senadores autonómicos, se entiende ya enraizada en nuestra cultura política $^{19}$. La existencia de estos senadores permite, al encarar la nueva composición del Senado, valorar la experiencia desarrollada en estos años, a la vez que articular la representación de las Comunidades Autónomas en la Cámara Alta sin que sea una idea nueva a introducir desde cero, con la que la opinión pública tenga que familiarizarse sin ninguna referencia teórica que le sirva de punto de apoyo ${ }^{20}$.

Sin embargo, inclinarse por una u otra opción, y en particular por la designación por los Parlamentos autonómicos, no resuelve todos los problemas, sino que se hace necesario resolver una serie de cuestiones conexas, cuya combinación dará como resultado, una vez resueltas las incógnitas, la composición del futuro Senado.

\section{B) Cuestiones conexas}

Es a estas cuestiones a las que vamos a dedicar nuestra atención a continuación. En todas ellas suele haber una visión doctrinal utópica, un tanto alejada de la realidad, y otra más pragmática, basada en la práctica y la experiencia parlamentarias. Me limitaré a plantear en este breve catálogo de problemas las posiciones posibles.

\section{1) Número de senadores}

Muchas propuestas se han hecho a este respecto, que oscilan desde una restricción drástica en el número de senadores a una ampliación que permita ajustar la distribución entre Comunidades Autónomas. Incidentalmente señalaré que los senadores suelen considerar que una gran reducción en su número podría afectar negativamente al ejercicio de las funciones del Senado, por ser difícil asumir las labores de la Cámara con un número limitado de miembros ${ }^{21}$.

19 R. PUNSET BLANCO, "La territorialización del Senado y la reforma de la Constitución", en Revista Española de Derecho Constitucional, n. ${ }^{\circ}$ 37, 1993, págs. 86 y ss. En el mismo sentido, A. TORRES DEL MORAL, "El Senado”, cit., pág. 366.

20 En cualquier caso, tampoco en esta opción, como señala R. BLANCO VALDÉS («La reforma del Senado", cit., pág. 43), hay razones para suponer que tras la reforma los senadores vayan a comportarse de manera distinta a los actuales senadores de elección autonómica indirecta, como senadores de partido que votan en función de la disciplina de partido y no de una hipotética vinculación territorial, por lo que no representan el interés de su respectivo territorio.

21 También R. PUNSET BLANCO («El Senado como Cámara de las Comunidades Autónomas. Bases de una propuesta", en El Senado, Cámara de representación territorial, III Jornadas de la 
En favor de la reducción del número se ha manifestado Aja, quien piensa en una Cámara de 81 senadores que admita una mínima proporcionalidad, elevando de uno a tres el número fijado en el artículo 69.5 para cada Comunidad Autónoma, más uno por cada millón de habitantes ${ }^{22}$. Torres Del Moral, a su vez, propone un Senado de entre 84 y 100 miembros, el primero compuesto por tres senadores por Comunidad más uno por cada millón o fracción superior a 500.000; el segundo, aumentando los senadores fijos a cuatro o bien, solución por la que se inclina, confiriendo el carácter de senadores natos a los Presidentes de las Comunidades Autónomas ${ }^{23}$. Un número parecido sobre la base de una composición mixta proponen De Esteban y González Trevijano: unos noventa senadores elegidos a través de una doble vía: unos por sufragio universal directo y otros por los Parlamentos autonómicos ${ }^{24}$.

Una reducción mucho más moderada proponía Fernández Segado, ya en 1982; aunque se inclinaba por la elección por sufragio universal en la Comunidad Autónoma, defendía un Senado compuesto por cinco senadores por cada una de ellas, uno más por provincia que la integre y otro por cada 400.000 habitantes o fracción superior a 200.000, obteniendo así 227 senadores, porque no sería necesaria la sobrerrepresentación de los archipiélagos y se mantendrían los senadores para Ceuta y Melilla ${ }^{25}$. La oposición a que la elección la realicen las Asambleas se justifica porque puede implicar "un solapamiento de la representación de la Comunidad ante órganos del Estado con la representación regional propiamente dicha", a la vez que la vinculación de los senadores con las Asambleas puede conducir a que estén más cerca de ser delegados de aquéllas que representantes de la Comunidad, "lo que conduce irremisiblemente a una especie análoga al mandato imperativo prohibido por nuestro texto constitucional". En este sentido, el autor referido es partidario de la incompatibilidad de las actas de senador y diputado autonómico.

Asociación Española de Letrados de Parlamentos, Tecnos, Madrid, 1996, pág. 172), opina que un número menor al actual afectaría negativamente a la agilidad del trabajo del Senado, sobre todo si se mantienen los breves plazos establecidos por el artículo $90 \mathrm{CE}$ en el ámbito del procedimiento legislativo.

22 E. AJA, "Perspectivas de la reforma constitucional del Senado», cit., págs. 221-222. Para una segunda Cámara modelo Bundesrat, en El Estado autonómico. Federalismo y hechos diferenciales, cit., págs. 260 y ss., propone que cada Comunidad Autónoma tuviera tres votos como mínimo, más uno por millón de habitantes, lo que daría un total de 85 miembros.

23 A. TORRES DEL MORAL, "El Senado", cit., pág. 365. Un Senado de 82 miembros, de tipo Bundesrat, propone J. VINTRÓ CASTELLS en "Una propuesta sobre la composición y las funciones del Senado", en El Senado, Cámara de representación territorial, III Jornadas de la Asociación Española de Letrados de Parlamentos, Tecnos, Madrid, 1996, pág. 187, a base de tres Senadores por Comunidad más uno por cada millón de habitantes.

24 J. DE ESTEBAN y P. GONZÁLEZ TREVIJANO, Curso de Derecho Constitucional español, Facultad de Derecho de la Universidad Complutense, Madrid, 1994, pág. 627.

25 F. FERNÁNDEZ SEGADO, "El bicameralismo y la naturaleza del Senado”, cit., págs. 109 y ss. Opina que así se consigue una representación equilibrada, con diferencias de 7 a 28 senadores (el cuádruple, escala parecida a Austria), que, salvo el sistema ofrecido por el artículo 60 del Anteproyecto de Constitución, son menores que las que presentan los otros sistemas que se barajaron a lo largo del iter constituyente. 
Cuando se pretende elevar el número de senadores es, como hemos señalado, con el deseo de poder efectuar una más adecuada distribución entre las actuales Comunidades Autónomas, segunda cuestión que se nos plantea de inmediato.

\section{2) Criterios de distribución del número de senadores por Comunidades Autónomas}

Del número fijo (próximo a los Estados federales) a la proporcionalidad con la población, caben posiciones intermedias, como la actual de mínimo común y adición en función de la población. La proporcionalidad actual ha sido criticada por la doctrina, por las diferencias en la representación que conlleva ${ }^{26}$. Un cambio en la distribución actual es el propuesto por Fraga Iribarne; tomando como base los actuales senadores designados, en el debate sobre la situación del Estado de las autonomías de 1994, como Presidente de la Comunidad Autónoma de Galicia ante la Comisión General de las Comunidades Autónomas $^{27}$, formuló una propuesta de composición de la Cámara Alta en el sentido siguiente, más conservador respecto del actual: reducir los senadores provinciales a tres por circunscripción y a dos los correspondientes a las islas mayores; elevar el número de senadores designados por las Comunidades Autónomas hasta un total del doble de provincias que componen la Comunidad,

26 Sobre las desigualdades en la representación entre provincias y Comunidades Autónomas, véase M. MARTÍNEZ SOSPEDRA, "Desigualdad y representación en la Constitución española de 1978: el caso de las Cortes Generales", en Parlamento y sociedad civil (Simposium), Universidad de Barcelona, 1980, en particular págs. 191-195, y V. BOSCH i PALANCA, "El Senado como ejemplo de deformación electoral", en Historia, Política y Derecho. Estudios en Homenaje al Profesor Diego Sevilla Andrés, Universidad de Valencia, 1984. En otro trabajo, esta autora llega a afirmar categóricamente que las distorsiones introducidas por la igualdad en el número de senadores entre provincias, con el desequilibrio poblacional tan acentuado que éstas presentan, que sitúan en una relación de uno a treinta y ocho la correspondencia senador/habitante entre la provincia de mayor y menor población, invalidan cualquier pretensión de calificar democráticamente al Senado así configurado" (La representación provincial y la representación autonómica: el caso del Senado español, en Problemas actuales del Estado social y democrático de derecho, Universidad de Alicante, 1985, pág. 328). Sin llegar a estos extremos, también M. CACIAGLI destaca que, evidentemente, la "disrepresentación" ( $i$ ic) resulta favorable, de modo acentuado, a las provincias menos pobladas ("El sistema electoral de las Cortes según los artículos 68 y 69", en La Constitución española de 1978. Estudio sistemático dirigido por los profesores Alberto Predieri y Eduardo García de Enterría, Civitas, Madrid, 1988, pág. 541).

No obstante, L. SÁNCHEZ AGESTA puso de relieve que, en la medida que se quiera integrar a las minorías en un órgano de decisión común de carácter representativo (hecho en el que se traduce el regionalismo, y no sólo en la concesión de una autonomía), esa Cámara u órgano no puede tener base en un principio de equitativa proporcionalidad de la población, concediendo a las regiones una representación como tales regiones, con independencia de su población (El sistema político de la Constitución española de 1978, Editora Nacional, Madrid, 1980, pág. 268).

27 Diario de Sesiones de Comisiones, Senado, V Legislatura, núm. 128, 26 de septiembre de 1994, pág. 23. Véase también M. FRAGA IRIBARNE, Impulso Autonómico, Planeta, Barcelona, 1994, págs. 53 y ss. 
además del senador por cada millón de habitantes; e incluir como miembros del Senado a los Presidentes de las Comunidades Autónomas. Asimismo, proponía que los senadores de designación deban poseer la condición de miembros de la Asamblea legislativa de la Comunidad Autónoma, para garantizar la fluidez entre la sensibilidad de los parlamentarios autonómicos y la Cámara de representación territorial.

Algún otro autor, sobre la base de la elección en circunscripción única, propone un Senado compuesto por cuatro senadores por Comunidad Autónoma, más uno por provincia (criterio suprimible, que reduciría el número de senadores en 50) y un senador más por millón de habitantes o fracción superior a 500.000 , dando un Senado de 160 miembros $^{28}$.

Es obvio que, incluso en este tema de la composición, se entremezclan factores de hondo calado político y relacionados con el Título VIII de la Constitución, como es el problema sustancial de si el llamado hecho diferencial o la existencia de Comunidades de distinto nivel inicial de competencias, por decirlo abreviadamente, ha de tener un reflejo en la composición de la Cámara Alta. Es probable que éste sea el tema político de mayor trasfondo ante la eventual reforma del Senado, tanto en cuanto a composición como a aspectos de su funcionamiento, en particular la forma de adopción de acuerdos.

\section{3) Relación entre el Parlamento designante y los senadores designados}

¿Ha de abolirse, si se opta por la elección de senadores por los Parlamentos autonómicos, la prohibición de mandato imperativo contenida en el artículo 67.2 de la Constitución? De conformidad con el artículo 66 de la Constitución, «las Cortes Generales representan al pueblo español». Esta afirmación, completada con la prohibición del mandato imperativo contenida en el artículo 67.2, relativiza la relación de diputados y senadores con la circunscripción por la que fueron elegidos o con la Comunidad Autónoma por la que fueron designados.

No obstante, con carácter general se identifica a los senadores del artículo 69.5 de la Constitución como senadores representantes de las Comunidades Autóno$m a s^{29}$, y así aparecen en algunos Estatutos de Autonomía, como los de País Vasco, Cataluña, Galicia, Cantabria, La Rioja, Comunidad Valenciana, CastillaLa Mancha,

28 P .J. HERNANDO GARCÍA, "Algunos interrogantes ante la futura reforma del Senado", en El Senado, Cámara de representación territorial, III Jornadas de la Asociación Española de Letrados de Parlamentos, Tecnos, Madrid, 1996, págs. 292 y ss, donde estudia el resultado de esta composición sobre la paridad en la representación de las distintas Cámaras.

29 En alguna ocasión se les atribuye incluso la representación de los Parlamentos autónomos. Así, la Sentencia del Tribunal Constitucional de 18 de diciembre de 1981 (FJ 3), cuando afirma que, "acabado el mandato del Senado antes de finalizar (el) del Parlamento vasco, se compromete éste a seguir representado por los Senadores anteriormente designados". 
Canarias, Islas Baleares, Madrid y Castilla y León ${ }^{30}$. Es esta vinculación específica la única que permite hablar con cierta propiedad de la representación territorial del Senado y la que diferencia su forma de elección, en cuanto a las circunscripciones electorales, respecto del Congreso de los Diputados ${ }^{31}$.

Sin embargo, como decíamos, esta vinculación ha de entenderse siempre enmarcada en el artículo 66.1 de la Constitución. En nuestra doctrina, Fernández Segado apunta que los senadores autonómicos «vienen a ostentar en cierto sentido (pues en sentido estricto las Cortes Generales representan al pueblo español y sus miembros no están ligados por mandato imperativo) la representación directa de las Comunidades Autónomas ${ }^{32}$. Trujillo señalaba que, aunque jurídicamente es exacta la afirmación de que debe matizarse la expresión Cámara de representación territorial por la aplicación de la prohibición del mandato imperativo, no por ello deben desconocerse las especiales vinculaciones que la práctica habrá de establecer por las vías siguientes: a) la dependencia fáctica de los senadores designados de la Comunidad que los designa, y b) el sistema de partidos imperante en cada Comunidad, que determinará que el grupo o coalición mayoritario en la misma incorpore a su disciplina el mayor número de senadores designados por la misma dentro de la "adecuada representación proporcional. Es en este sentido, añade Trujillo, en el que, previsi-

30 Art. 28 a) EA País Vasco: "Senadores que han de representar al País Vasco, según lo previsto en el art. 69.5 de la Constitución"; fórmula similar en el art. 10.1 c) EA Galicia, art. 17.1 k) EA La Rioja y art. 11 j) EA Comunidad Valenciana. Art. 34.1 EA Cataluña: "Senadores que representarán a la Generalidad en el Senado". Art. 9.1 h) EA Cantabria: "Senadores representantes de la Comunidad Autónoma Cántabra, de acuerdo a lo previsto en el art. 69 apdo. 5 de la Constitución"; fórmula similar en el art. 9.2 e) EA CastillaLa Mancha. Art. 12 d) EA Canarias: «Senadores representantes de la Comunidad Autónoma de Canarias". Art. 28.1 EA Baleares: "Senadores que han de representar a la Comunidad en el Senado de acuerdo con lo establecido en el art. 69.5 de la Constitución"; fórmula similar en el art. 14.12 EA Madrid y art. 13.5 EA Castilla y León.

Frente a éstos, véanse el art. 30.12 EA Andalucía: "Senadores que correspondan a la Comunidad Autónoma de acuerdo con el art. 69.5 de la Constitución" [fórmula similar en el art. 20.1 d) EA Extremadura]; art. 24.2 EA Asturias: "Senadores a que se refiere el art. 69.5 de la Constitución" [fórmula similar en el art. 23.1 EA Región de Murcia y art. 16 b) EA Aragón] o art. 12 LORAF Navarra: "Senadores que pudieran corresponder a Navarra como Comunidad Foral".

31 Dice F. SANTAOLALLA que el hecho de que las funciones de un órgano tengan carácter territorial nada tiene que ver con el concepto de representación, que no puede derivarse de otra cosa que del procedimiento de selección de los miembros del órgano de que se trate (El Parlamento en la encrucijada, cit. pág. 75). Un estudio sobre el concepto de representación territorial, en R. PUNSET, "El concepto de representación territorial en la Constitución española de 1978", en Revista de Derecho Político, n. ${ }^{\circ}$ 7, 1980, págs. 105-118.

32 F. FERNÁNDEZ SEGADO, "El sistema constitucional español", en Los sistemas constitucionales iberoamericanos, Dykinson, Madrid, 1992, pág. 451. F. J. GARCÍA ROCA ("Comentario al artículo 20 del Estatuto de Autonomía de Extremadura", en Comentarios al Estatuto de Autonomía de Extremadura, dirigidos por A. Torres del Moral, UNED, Mérida, 1985, págs. 220-221) considera que los intereses de la Comunidad extremeña como corporación territorial "deben ser defendidos unitariamente por los senadores de designación autonómica", aun reconociendo que con ello se contribuye a "una orientación política nacional fruto de la transacción entre múltiples intereses comunitarios concretos", con lo que su labor puede entenderse como parte de una más amplia función de orientación política de toda la Asamblea. 
blemente, quepa hablar en el futuro del Senado como Cámara de "representación territorial, ${ }^{33}$.

A su vez, Caamaño Domínguez recuerda que, en las segundas Cámaras territoriales de modelo "Senado" (frente al modelo "Consejo", que implica una opción diametralmente distinta en la regulación jurídica del mandato de sus miembros), destaca la absoluta independencia del representante respecto al órgano o al cuerpo electoral del ente descentralizado que lo ha designado, sin estar sometido jurídicamente a instrucción o directriz alguna y sin que sea posible una revocación anticipada de su mandato por el ente designante (como veremos a continuación que ocurre con los senadores designados), de forma que la territorialidad de su representación sólo es exigible en términos políticos, pero nunca en el plano de lo jurídico, al recaer sobre su estatuto la prohibición constitucional del mandato imperativo ${ }^{34}$. En este sentido, más que de representación territorial cabría hablar de la representatividad territorial de las segundas Cámaras, como cualidad de diferenciación articulada competencialmente, pero fundamentada en la distinta modalidad de reclutamiento de sus miembros y caracterizada por la intervención $a b$ origine de los entes descentralizados.

Frente a este modelo, en el tipo "Consejo", ejemplificado en el Bundesrat alemán, las segundas Cámaras asumen jurídicamente la territorialidad de su representación y la sustantivizan mediante la vinculación jurídica de sus miembros a las decisiones adoptadas en el ente designante, con lo cual se convierten en mandatarios instruidos o en delegados institucionales ante un órgano del Estado central, susceptibles de ser revocados en todo momento ${ }^{35}$.

Por otra parte, la designación por los grupos parlamentarios-partidos políticos produce de hecho la homogeneización de su papel en el Senado ${ }^{36}$, porque los senadores se alinean sin excepción con su grupo parlamentario nacional. En este sentido, si, como se ha afirmado, los senadores designados representan una esfera de intereses determinados, lo que según Chueca de un modo u otro constituye una derogación del principio del mandato representativo, lo cu-

33 G. TRUJILLO, «Federalismo y regionalismo en la Constitución Española de 1978: el Estado "federoregional", en Federalismo y regionalismo, obra coordinada por el mismo autor, CEC, Madrid, 1979, pág. 35.

34 F. CAAMAÑO DOMÍNGUEZ, El mandato parlamentario, Congreso de los Diputados, Madrid, 1991, pág. 189.

35 E. ALBERTI ROVIRA (Federalismo y cooperación en la República Federal Alemana, CEC, Madrid, 1986, págs. 145 y ss) señala cómo esta especial naturaleza de su mandato, en oposición a la libertad de voto que rige como norma general en los demás regímenes federales, viene determinada expresamente por la Ley Fundamental de Bonn (artículo 51.3) y se presenta como el resultado del fundamento gubernamental de la representación de los Länder, en contraposición a una representación individual, de la que también se sigue la unidad de votos de cada Land. Los miembros del Bundesrat representan la voluntad de sus respectivos gobiernos que, por delegación, sólo puede exteriorizarse de forma unitaria y no plural. Sólo están liberados del poder de instrucción los miembros del Bundesrat cuando participan en la Comisión de Conciliación (artículo 77.2 LF) o en la Comisión Conjunta (artículo 53.9,1 LF).

36 R. CHUECA RODRÍGUEZ, "Teoría y práctica del bicameralismo en la Constitución española", en Revista Española de Derecho Constitucional, n. ${ }^{\circ} 10$, 1984, pág. 83. 
rioso es que son los partidos políticos quienes, mediante la vía fáctica de la dependencia representante-partido, tan denostada, reconducen a esos representantes a una situación igualmente representativa que la del resto de los miembros de las Cámaras ${ }^{37}$.

La abolición de la prohibición del mandato imperativo para los senadores, que sería clara en el caso de optar por un Senado compuesto por representantes de los Gobiernos autonómicos, no resultaría indispensable, ni siquiera plenamente coherente, si se trata de unos senadores elegidos en los Parlamentos autonómicos con un sistema proporcional, pues sería difícil en tal caso articular la formulación de instrucciones (¿por mayoría cualificada?) a los elegidos o hallar una forma de revocabilidad que respetara a las minorías.

4) Compatibilidad del mandato de senador con el de parlamentario autonómico

Recordemos que el artículo 67.1 de la Constitución permite la acumulación de las actas de senador y de diputado autonómico, prohibida expresamente a los miembros del Congreso de los Diputados. La diferencia de trato se justifica, en primer término, por la proclamación del Senado como Cámara de representación territorial por el artículo 69.1 de la Constitución, siendo uno de los escasos preceptos en que tal declaración se refleja o hace realidad ${ }^{38}$. Se lograría así, según Fernández Segado, que ocupasen escaños en la Cámara Alta portavoces especialmente cualificados para la defensa específica de intereses de los territorios que integran el Estado, por el conocimiento adquirido en el desarrollo de la vida parlamentaria de una Asamblea legislativa autonómica ${ }^{39}$. Recoder De Casso añade a esta motivación para la diferencia de trato con el Congreso el diseño constitucional de un Senado privado de capacidad decisoria sustancial, salvo en cuestiones internacionales o relacionadas con las Comunidades Autónomas, con lo que se soslaya el riesgo de favorecer la centralización que es propia de la acumulación de mandatos ${ }^{40}$. De Vega sitúa también

37 R. CHUECA RODRÍGUEZ, «La representación como posibilidad en el Estado de partidos (Mandato libre vs. mandato de partido)», en Revista de Derecho Político, núm. 27-28, 1988, pág. 30 (subrayado del autor).

38 A veces se producen en la práctica movimientos contrarios a esta tendencia: por ejemplo, según información de la prensa, un senador cabeza de lista en las elecciones al Parlamento Vasco celebradas en octubre de 1994 renunció a su escaño autonómico "para participar activamente como senador en la reforma de la Cámara Alta".

39 F. FERNÁNDEZ SEGADO, "El bicameralismo y la naturaleza del Senado", cit., pág. 93. Sin embargo, este autor estima que hubiera sido preferible que la prohibición de acumulación de actas se extendiera también al Senado, como ocurre en el artículo 35.2 de la Constitución federal austriaca (aunque los miembros del Bundesrat deben reunir los requisitos de elegibilidad para la Asamblea que les envía).

40 E. RECODER DE CASSO, "Comentario al artículo 67", en Comentarios a la Constitución, dirigidos por Fernando Garrido Falla, Civitas, Madrid, 1980, pág. 1032), quien recoge otros inconvenientes de la acumulación, como son la falta de disponibilidad del elegido, el absentismo parlamentario y el entorpecimiento que supone para una renovación de la clase política. 
la cuestión de la acumulación de mandatos no en la órbita de la compatibilidad o la elegibilidad, sino en la esfera de las relaciones de inordinación, en virtud de la cual se trata de insertar las peticiones, derechos e intereses de las Comunidades en el aparato institucional del Estado ${ }^{41}$.

De la experiencia actual de posibilidad, no impuesta, de acumulación de mandatos ${ }^{42}$ ha resultado curiosamente la tendencia contraria a la compatibilidad de actas, por entender que afecta negativamente a los trabajos de la Cámara autonómica, sobre todo en caso de mayorías ajustadas, que precisan de una dedicación más plena de los parlamentarios autonómicos, en particular cuando se trata de Comunidades geográficamente alejadas de las Cortes Generales (Baleares, Canarias). Esta tendencia, que podríamos llamar inversa respecto de la primera hacia la acumulación de mandatos, se ha plasmado en los ordenamientos autonómicos eliminando la exigencia de la condición de diputado para ser designado senador (Baleares, Castilla y León, Castilla-La Mancha) o exigiendo la renuncia a tal condición (Canarias).

Sin embargo, al menos desde un punto de vista teórico y simbólico, el doble mandato repercute en una vinculación entre Senado y Cámara autonómica, que refuerza el carácter territorial de la primera y la integración de los intereses territoriales en un órgano del Estado. A pesar de las dificultades prácticas que puede suponer para los afectados la dualidad de mandatos representativos, hay razones que abogan por la presencia en la Cámara Alta de personas significativas en la vida política de las respectivas Comunidades Autónomas, a través de las cuales el Senado cumple efectivamente su función de integración de los elementos territoriales ${ }^{43}$. En este sentido, su existencia merece una valoración positiva: resulta enriquecedor aportar la visión de la política de un órgano legislativo nacional a un órgano centrado en la política autonómica, y viceversa.

\section{5) Duración del mandato. Posibilidad de disolución}

En este breve catálogo de cuestiones unidas a la composición de la Cámara no puede faltar la alusión a la duración del mandato de los senadores, su eventual conexión con el mandato de los Parlamentos autonómicos, y, finalmente, la posibilidad o no de disolución de la Cámara. Deteniéndonos en este

41 P. DE VEGA, "Comentario al artículo 67 de la Constitución", en Comentarios a las leyes políticas: Constitución española de 1978, dirigidos por O. Alzaga Villaamil, Edersa, tomo VI, Madrid, 1989, pág. 35.

42 Por lo que no se trata de las que M. REYDELLET denomina "acumulaciones obligatorias", como la existente en Francia ("Le cumul des mandats", en Revue de Droit Public, enero-febrero 1979, págs. 701 y ss).

43 Las soluciones en Derecho comparado son diversas: mientras que en Italia, por ejemplo, se prohíbe la compatibilidad, en Francia, por el contrario, se impone obligatoriamente. Es frecuente que se afirmen las connotaciones centralistas de la acumulación de mandatos, aunque tal vez sería más correcto hablar (como se hace en el texto) de las cualidades de integración que ofrece el doble mandato. Véase M. REYDELLET, op. cit., págs. 693 y ss., y el estudio del Senado francés, «Le cumul des mandats electifs", en Sénat [Études], n. ${ }^{\circ} 71,1995$. 
último punto, recordemos que, en Derecho comparado, la Cámara excluida de la relación de confianza con el Gobierno no es objeto de disolución. La regla general es que las Cámaras Altas no sean susceptibles de disolución, salvo cuando el Gobierno necesita de su confianza. En Europa occidental no son susceptibles de disolución el Senado irlandés, el francés, el Bundesrat alemán y los Consejos suizo y austriaco, ni tampoco, obviamente, la Cámara de los Lores. Sí lo son el Senado belga, el italiano y la primera Cámara holandesa. Se desprendería de esta enumeración (con excepciones) que no son susceptibles de disolución las Cámaras de representación territorial ${ }^{44}$. En este punto, nuestra Constitución se separa de las líneas maestras imperantes en las segundas Cámaras al tratar el problema del mandato de los senadores y su duración: mayor duración del mandato de la Cámara Alta, renovación parcial e indisolubilidad.

Santaolalla cree que la solución adoptada es enteramente criticable, dado que no se compagina con el tipo de parlamentarismo escogido, donde la relación de confianza se produce respecto del Congreso de los Diputados y nunca respecto del Senado $^{45}$. Con ello se une a aquellos autores contrarios a la posibilidad de disolver el Senado, por entender que tan sólo es coherente y justificado para esta Cámara el supuesto de disolución previsto en el artículo 168.1 de la Constitución, mientras que los otros dos casos (artículos 99 y 115) responden a la relación Congreso-Gobierno, en la que el Senado no interviene, de forma que es sancionado por actos que no ha cometido, víctima de un paralelismo sin sentido. Estos dos supuestos fueron calificados de paradójicos por González Encinar ${ }^{46}$. En el mismo sentido, Punset entiende

44 Véase J. C. COLLIARD, Los regímenes parlamentarios contemporáneos, Blume, Barcelona, 1981, págs. 69-72, y, entre nosotros, V. BOSCH i PALANCA, "La representación provincial y la representación autonómica: el caso del Senado español", cit., pág. 343, donde se examina la duración del mandato en los distintos países.

45 F. SANTAOLALLA LÓPEZ, "Comentario al artículo 115 de la Constitución", en Comentarios a la Constitución, dirigidos por Fernando Garrido Falla, Civitas, Madrid, 1985, pág. 1549. X. ARBÓS («El Senado: marco constitucional y propuesta de reforma", cit., pág. 32) entiende que pueden suprimirse los supuestos de disolución de los artículos 99.5 y 115.1 respecto del Senado. La misma propuesta, en V. BOSCH i PALANCA ("La representación provincial y la representación autonómica: el caso del Senado español", cit. pág. 345) y A. BAR CENDÓN [Sobre una hipotética reforma de la potestad de disolución de las Cámaras legislativas prevista en el artículo 115 de la Constitución", en Revista de Derecho Político, núm. 37 (La reforma constitucional), 1992, págs. 156-157] se apoya en la semejanza del Senado español (considerándolo Cámara no territorial) con las Cámaras belga, italiana y holandesa citadas (en cuanto que son electivas y con funciones muy similares a la Cámara baja), así como en nuestro constitucionalismo histórico — además de en motivaciones de tipo funcional y político (la gravedad de la situación requiere la renovación electoral total y, por otra parte, el Senado no es ajeno al control de la actividad gubernamental)_, para afirmar que la regulación del artículo 115.1 es perfectamente razonable (La disolución de las Cámaras legislativas en el ordenamiento constitucional español, Congreso de los Diputados, Madrid, 1989, págs. 214 y 173 y ss).

46 "Bicameralismo", en Diccionario del sistema político español, Akal, Madrid, 1984, págs. 43-44.

47 R. PUNSET, "El Senado en la nueva Constitución española”, cit., pág. 159. Véase también de este autor, sobre la escasa justificación de la posibilidad de disolución en solitario del Senado y los problemas que suscitaría (entre ellos la paralización legislativa de la Cámara baja), ibidem, págs. 149-151, y "La estructura bicameral de las Cortes Generales", en Lecciones de Derecho constitucional. Órganos constitucionales, Guiastur, Oviedo, 1980, págs. 95 y ss. 
que hay exageración e incongruencia en los dos tipos de disolución ${ }^{47}$. Piqueras Bautista $^{48}$, por su parte, afirma que la propia Constitución refleja esta incongruencia cuando, en el caso de declaración de estados de alarma, excepción o sitio, no permite disolver el Congreso, pero sí el Senado.

Otras opiniones: Lucas Verdú, en referencia al Anteproyecto de Constitución, consideraba que la introducción de la disolución del Senado debía de ser un lapsus gramatical o, si se había incluido conscientemente, revelaba un temor infundado al moderado control político del Gobierno por el Senado o que los redactores pensaban, también infundadamente, que el Anteproyecto había establecido, en punto a control político, un bicameralismo perfecto ${ }^{49}$. Molas, a su vez, aventura como única razón posible para incluir la disolución del Senado que, siendo las Cortes Generales una unidad legislativa, como el electorado puede variar su opinión en las nuevas elecciones, es lógico que las dos Cámaras respondan en su composición a una misma expresión unitaria de volun$\operatorname{tad}^{50}$. En el mismo sentido, Fernández-Miranda Alonso apunta que la necesidad de paralelismo en el mandato de las Cámaras podría truncarse por un fin del mandato no simultáneo, que además rompería la unidad del resultado electoral $^{51}$. Santaolalla también piensa que el único motivo que puede explicar la disolución del Senado es no obligar a convocar unas elecciones separadas para esta Cámara cuando su mandato dejara de coincidir con el Congreso por disolución de éste, con el riesgo de provocar un cansancio electoral en la opinión pública $^{52}$. Por su parte, Espín considera que la única justificación para la solución dada sería el ahorro electoral que significan unas elecciones generales en lugar de dos procesos independientes ${ }^{53}$. Argumentos parecidos a los expuestos en favor de la disolución simultánea de las Cámaras deben haber pesado al in-

48 "Disolución de las Cortes Generales y de los Parlamentos Autonómicos", en Las Cortes Generales, Instituto de Estudios Fiscales, Madrid, 1987, vol. III, pág. 1968.

49 P. LUCAS VERDÚ, "El control por el Senado de la política gubernamental (¿Responsabilidad política del Gobierno ante el Senado?)", en El control parlamentario del Gobierno en las democracias pluralistas, Manuel Ramírez (ed.), Labor, Barcelona, 1978, pág. 367.

50 I. MOLAS, "La disolución del Parlamento", en Parlamento y sociedad civil (Simposium). Universidad de Barcelona, 1980, págs. 99-100. El autor explica el refrendo del Presidente del Congreso para la disolución automática del artículo 99.5 por el hecho de disolverse las Cortes Generales en un solo acto y por tanto, con un solo refrendo, mediante el que el Presidente del Congreso, que por otra parte preside las sesiones conjuntas de las Cámaras (artículo 73.2), "Se convierte en una pieza que trasciende la Cámara que preside para poder realizar funciones de las Cortes Generales como tales, aun sin llegar a ser Presidente de las mismas" (págs. 100-101).

51 F. FERNÁNDEZ-MIRANDA ALONSO, "La regulación del Gobierno en la Constitución", en Lecturas sobre la Constitución Española, Universidad Nacional de Educación a Distancia, Madrid, 1978, vol. II, págs. 620-637. Se inclina por el acompasamiento de las elecciones parlamentarias ordinarias, aunque sea a costa de disolver anticipadamente una de las Cámaras cuando transcurra el mandato de la otra, que fue disuelta previamente (pág. 637).

52 F. SANTAOLALLA LÓPEZ, "Comentario al artículo 115", cit., pág. 1550, quien cree "innecesaria y complicada" la posibilidad de disolver el Senado (Derecho parlamentario español, Editora Nacional, Madrid, 1984, pág. 73).

53 En J. DE ESTEBAN y L. LÓPEZ GUERRA, El régimen constitucional español, Labor, Barcelona, 1982, vol. 2, pág. 305, nota 477. 
corporar a la Constitución belga (artículo 46), tras su reforma de 1993, la novedad de que la disolución de la Cámara de representantes lleve aparejada la del Senado.

Hay opiniones divergentes, menos críticas con nuestra regulación constitucional, que conviene asimismo recoger. Así, Manzella cree que la introducción de la posibilidad de disolver el Senado corresponde a la configuración constitucional del mismo como partícipe en el control, no en el momento de la investidura, pero sí en el desarrollo del programa político del Gobierno ${ }^{54}$. Bar Cendón, además de este argumento, aduce como lógico el que se tienda a una cierta homogeneidad en la representación política y en el apoyo al Gobierno en ambas Cámaras, para evitar el riesgo de confrontación y obstruccionismo entre ellas y respecto del Gobierno, y que a la vez se busque una economía procedimental y financiera ${ }^{55}$. También Fernández Segado considera razonable ("flexible y afortunada") la posibilidad de disolución de una u otra Cámara alternativamente, censurando en cambio que redacciones anteriores del artículo 115 impusiesen la disolución forzada de ambas Cámaras al unísono. Frente a la doctrina expuesta que critica el hecho de que pueda disolverse una Cámara que no tiene la posibilidad de hacer caer al Gobierno ni competencias equivalentes a la Cámara Baja, recuerda este autor que hay algunas circunstancias que pueden aconsejar la disolución conjunta de ambas Cámaras ${ }^{56}$. De ahí que considere «relativamente positiva" la redacción del artículo 115 (a la vez que tacha de absolutamente desafortunada e ilógica la prescripción del artículo 99.5, tras el fracaso de las votaciones de investidura), aun cuando coincide con Martínez Sospedra ${ }^{57}$ en que, en principio, lo más coherente sería respetar en la medida de lo posible el mandato del Senado por las razones antes reseñadas; por ello, no le parece beneficioso que la praxis política institucionalice la disolución conjunta de ambos cuerpos legislativos, convertida en regla habitual, que desvirtúa la mayor ventaja de la solución del artículo 115.1: su flexibilidad. En el mismo sentido, Recoder ${ }^{58}$ y Elizalde ${ }^{59}$ abogan por la utilización de la posibilidad de disolución separada del Congreso atribuida por el artículo 115, que permita al Se-

54 A. MANZELLA, “Las Cortes en el sistema constitucional español”, en La Constitución española de 1978. Estudio sistemático dirigido por los profesores Alberto Predieri y Eduardo García de Enterría, Civitas, Madrid, 1988, pág. 500.

55 A. BAR CENDÓN, La disolución de las Cámaras legislativas en el ordenamiento constitucional español, Congreso de los Diputados, Madrid, 1989, págs. 173 y ss.

56 F. FERNÁNDEZ SEGADO, "Comentario al artículo 115 de la Constitución", en Comentarios a las leyes políticas: Constitución española de 1978, dirigidos por Óscar Alzaga Villaamil, Edersa, tomo IX, Madrid, 1987, págs. 213 y ss. Véase también "Reflexiones en torno a la reforma constitucional del Senado", cit., pág. 200.

57 M. MARTÍNEZ SOSPEDRA, Aproximación al Derecho constitucional español. La Constitución de 1978, Fernando Torres Editor, Valencia, 1980, pág. 193.

58 E. RECODER DE CASSO, "Comentario al artículo 69 de la Constitución", en Comentarios a

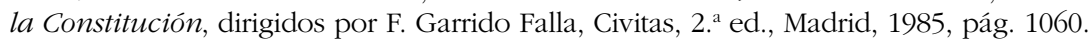

59 J. ELIZALDE, "Comentario al artículo 69 de la Constitución", en Comentarios a las leyes políticas: Constitución española de 1978, dirigidos por Óscar Alzaga Villaamil, Edersa, tomo VI, Madrid, 1989, pág. 227. 
nado concluir sus ciclos cuatrienales, creando una pauta de diferenciación temporal con las elecciones al Congreso de los Diputados, "muy saludable... para la propia diferenciación institucional de la Cámara territorial", según el autor antes mencionado.

Sobre el papel, es evidente que la disolución separada del Senado no carece de atractivo, en cuanto aportaría a aquél una vida política y electoral propia que pudiera contribuir a definir su personalidad institucional. Parece, no obstante, que ello es posible con el actual enunciado del artículo 115.1, que a su vez permite conjugar estas motivaciones con otras de racionalidad política, que en ocasiones pueden exigir elecciones simultáneas de ambas Cámaras. Lo criticable sería, en definitiva, el uso político que se haga de las atribuciones constitucionales y no el texto que las establece ${ }^{60}$.

De otra parte, en alguna ocasión se solicita el acompasamiento de las elecciones de senadores con las elecciones autonómicas (que se celebran en fechas distintas en las distintas Comunidades), lo que debería llevar consigo una Cámara permanente, de renovación gradual, con las consecuencias de acomodación del régimen de constitución de sus órganos rectores, por ejemplo.

En la doctrina, Torres Del Moral opta por una Cámara permanente, que se renovaría solamente tras cada constitución de los Parlamentos autonómicos, en concreto de los trece que lo hacen a la vez, en el mes de mayo cada cuatro años. Los designados por el resto de las Comunidades Autónomas se incorporarían conforme al ritmo electoral de cada una ${ }^{61}$. Gil-Robles también opina que la vinculación entre Senado y Asambleas legislativas de las Comunidades Autónomas se reforzaría si la renovación del Senado se hiciese coincidir con la elección de la mayor parte de aquéllas. De este modo, la elección de los senadores pasaría a formar parte del bloque de elecciones de representación territorial, en el que priman las consideraciones de representatividad y gobernabilidad locales y autonómicas sobre las estatales ${ }^{62}$.

\section{LAS FUNCIONES DEL SENADO}

Curiosamente, la cuestión más íntimamente relacionada con la composición de la Cámara es la de sus funciones.

Es éste el momento de recordar, a modo de advertencia inicial, la paradoja de Madison, enunciada por Déhousse: "La evolución de los regímenes fede-

60 Véase P. GARCÍA-ESCUDERO MÁRQUEZ y B. PENDÁS GARCÍA, “Senado y Gobierno: El Senado como Cámara de control," en Gobierno y Administración en la Constitución, Instituto de Estudios Fiscales, Madrid, 1988, vol. I, págs. 673-674.

61 A. TORRES DEL MORAL, "El Senado", cit., pág. 364.

62 J. M. ${ }^{a}$ GIL-ROBLES GIL-DELGADO, "El Senado en la Constitución española”, cit., pág. 30. Más recientemente, R. BLANCO VALDÉS, ("La reforma del Senado", cit., pág. 44) aboga por la renovación parcial del Senado acompasada con la de los Parlamentos autonómicos para asegurar la mejor correspondencia entre la voluntad de los territorios autonómicos y la de los senadores que los representan en la Cámara Alta. 
rales lleva a pensar que cuanto más importante sea el lugar de la Cámara Alta en el sistema institucional federal, más difícil le será cumplir la función representativa que le ba sido confiada "63.

Trasplantada esta paradoja a nuestro terreno y traducida a román paladino, viene a dar el principio siguiente: cuanto más territorial sea el Senado en su composición, mayor será la desigualdad de sus funciones respecto de la Cámara Baja elegida por sufragio universal, pasando entonces a ser una Cámara especializada, como ha ocurrido en Bélgica. Sólo cuando hay igualdad de origen democrático (y, por tanto, las mismas mayorías) se admite un bicameralismo perfecto. A mayorías distintas por distinta representación suelen corresponder funciones diferentes, cuestión esencial a tener muy en cuenta al decidir sobre la composición del futuro Senado.

Brevemente, la reforma en las funciones del Senado podría afectar básicamente a los aspectos siguientes:

\section{Procedimiento legislativo}

La delimitación del marco general de las propuestas de reforma en lo que se refiere a la posición del Senado en el procedimiento legislativo puede hacerse en torno a dos objetivos:

\section{a) Atenuar la posición subordinada del Senado ${ }^{64}$}

En general, puede decirse que existe el deseo de conservar el carácter del Senado como Cámara con competencia legislativa de carácter universal ${ }^{65}$ y, asimismo, mantener el predominio del Congreso de los Diputados, en cuanto

63 R. DÉHOUSSE, «Le paradoxe de Madison: réflexions sur le rôle des Chambres hautes dans les systèmes fédéraux", en Revue de Droit Publique et de la Science Politique en France et à l'Étranger, n. ${ }^{\circ}$ 3, 1990, pág. 647. De forma que, como señala R. PUNSET ("Razón e identidad del Senado", Revista española de Derecho Constitucional, n. ${ }^{\circ}$ 70, 2004, pág. 38), el bicameralismo resulta hoy tanto más perfecto e igualitario cuanto más próxima a la elección ciudadana esté la composición de la segunda Cámara. La pregunta que cabe hacerse, dice Punset, es si una Cámara de representación territorial, y por tanto necesariamente ajena al vínculo fiduciario con el Gobierno, puede aspirar a otra cosa que no sea el cumplimiento de la función de freno o garantía (pág. 41).

64 Para J. J. SOLOZÁBAL ECHAVARRIA ("Presupuestos y límites de la reforma constitucional del Senado", cit., pág. 64), la manifestación más clara del carácter descompensado de nuestro bicameralismo reside en la posición disminuida del Senado en relación con el Congreso en el procedimiento legislativo, opción rotunda del constituyente confirmada por el Reglamento parlamentario y aplicada además con cierta extremosidad en la práctica política.

65 Por todos, J. J. SOlOZÁBAL ECHAVARRÍA, ibidem, pág. 76; L. AGUIAR DE LUQUE, La participación del Senado en la función legislativa: una propuesta", en Ante el futuro del Senado, Instituto de Estudios Autonómicos, Barcelona, 19966, pág. 346; J. A. ALONSO DE ANTONIO, Estudios sobre la reforma del Senado, ed. autor, Madrid, 1999, pág. 170. En contra, M. GERPE LANDÍN, "La reforma del Senado", en Informe Pi i Sunyer sobre Comunidades Autónomas 1994, Fundació Carles Pi i Sunyer d'Estudis Autònomics i Locals, Barcelona, 1995, pág. 786: "el Senado intervendría exclusivamente en los ámbitos que afectaran a materia autonómica, quedando el resto de materias como competencia legislativa exclusiva del Congreso de los Diputados"; igualmente, pág. 789. 
Cámara de representación proporcional a la población ${ }^{66}$. Todo ello, teniendo en cuenta también lo ya expresado: a mayor territorialidad de la segunda Cámara, mayor desigualdad en el bicameralismo.

No obstante, se trataría de atenuar la situación actual de subordinación del Senado mediante distintas reformas posibles, que sintetizamos a continuación:

- Modificación de la tramitación primera en el Congreso de las proposiciones de ley tomadas en consideración por el Senado (89.2 CE) ${ }^{67}$.

- Posible toma en consideración por esta Cámara de las proposiciones de iniciativa autonómica ${ }^{68}$, que respondería también a la especialización territorial contemplada en el epígrafe siguiente.

- Modificación en el orden de tramitación de algunos proyectos de ley, a lo que nos referiremos asimismo en el epígrafe siguiente.

- Ampliación de los plazos constitucionales para la intervención del Senado en el procedimiento legislativo ${ }^{69}$.

- Modificación del sistema de resolución de las discrepancias entre las Cámaras, que podría ser similar al previsto en el artículo 74 CE para tres supuestos "territoriales" (sólo uno de ellos legislativo, el relativo al Fondo de Compensación Interterritorial): intervención de una Comisión mixta paritaria y, sólo en caso de mantenerse el desacuerdo, aprobación por el Congreso por mayoría absoluta ${ }^{70}$. Este sistema de resolución

66 R. PUNSET, El Senado y las Comunidades Autónomas, Tecnos, Madrid, 1987, pág. 233; «El Senado en el procedimiento legislativo, una reforma imposible", en El Parlamento y sus transformaciones actuales, A. Garrorena Morales, ed., Tecnos, Madrid, 1990, pág. 193. L. LÓPEZ GUERRA, "La reforma del procedimiento legislativo del Senado", en Ante el futuro del Senado, Instituto de Estudios Autonómicos, Barcelona, 1996, págs. 335-336: "la representación territorial implica casi forzosamente un "déficit democrático" del Senado que, a la luz del artículo 1 de la Constitución, debe conducir como principio general a que, en caso de contradicción entre las voluntades del Senado y el Congreso, predomine la de este último" (pág. 332). No nos planteamos siquiera la incidencia de una composición del Senado tipo Bundesrat sobre el procedimiento legislativo que, como dice P. BIGLINO CAMPOS, presenta algunos inconvenientes, que no cabe soslayar, de déficit democrático, no pareciendo adecuado que los Gobiernos de las Comunidades Autónomas, que no son órganos de naturaleza representativa, participen en el proceso de formación de una voluntad, la de la ley, que se imputa a los ciudadanos ("Veinticinco años de procedimiento legislativo", Revista de Derecho Político, n. ${ }^{\circ}$ 58-59, 2003-2004, pág. 466).

67 L. LÓPEZ GUERRA, "La reforma del procedimiento legislativo del Senado", cit., pág. 337.

68 R. PUNSET, El Senado y las Comunidades Autónomas, cit., pág. 229; A. TORRES DEL MORAL, "El Senado", cit., pág. 369.

69 En este sentido, L. LÓPEZ GUERRA, "La reforma del procedimiento legislativo del Senado", cit., pág. 336; J.A. ALONSO DE ANTONIO, Estudios sobre la reforma del Senado, cit., pág. 172.

70 Con variantes, en E. AJA FERNÁNDEZ ("Perspectivas de la reforma constitucional del Senado", cit., pág. 216), con desaparición del veto para las leyes "generales" no autonómicas; L. LÓPEZ GUERRA ("La reforma del procedimiento legislativo en el Senado", cit., pág. 337), aunque para algunos supuestos individualizados, no creando una categoría general de leyes que aumente la ya extrema complejidad del sistema de fuentes. J. J. SOLOZÁBAL ECHAVARRÍA ("Presupuestos y límites de la reforma constitucional del Senado", cit., pág, 66) cree que la generalización de las Comisiones mixtas debe alcanzar a la introducción de esa instancia de mediación en el supuesto de reforma constitucional total del artículo $168 \mathrm{CE}$. 
de conflictos podría afectar a todas las leyes o sólo a las de contenido autonómico que vemos en el epígrafe siguiente.

\section{b) Especialización territorial}

La segunda línea de propuestas va dirigida a que la naturaleza territorial del Senado, proclamada en el artículo 69.1 de la Constitución, tenga reflejo en su intervención en determinadas leyes de especial relevancia en el Estado autonómico.

En cuanto a la tramitación de estas leyes, las propuestas se centran en dos puntos:

- modificación del orden de intervención de las Cámaras, iniciando el Senado la tramitación ${ }^{71} \mathrm{y}$

- resolución de conflictos mediante Comisión mixta.

La relación de leyes incluidas en la categoría calificada "de incidencia autonómica" (Aja $\left.{ }^{72}\right)$, "de desarrollo autonómico" (Aguiar ${ }^{73}$ ), "de especial relevancia autonómica" (López Guerra ${ }^{74}$ ) o simplemente autonómicas ${ }^{75}$ no suele diferir mucho en la doctrina. Incluiría al menos:

- los Estatutos de Autonomía, es decir, las leyes orgánicas de reforma ${ }^{76}$

- las leyes previstas en el artículo 150 de la Constitución (leyes marco, de transferencia y delegación y de armonización)

71 L. LÓPEZ GUERRA, "La reforma del procedimiento legislativo del Senado", cit., pág. 337. M. GERPE LANDÍN, La reforma del Senado", cit., pág. 787.

72 E. AJA FERNÁNDEZ, "Perspectivas de la reforma constitucional del Senado", cit., pág. 217. En El Estado autonómico. Federalismo y hechos diferenciales, cit., pág. 253, propone que, en las leyes que afectan a competencias concurrentes y compartidas, la posición del Senado sea igual a la del Congreso, resolviéndose los conflictos mediante una Comisión Mixta paritaria, y en último término por el Congreso por una mayoría cualificada. En cambio, en las leyes en materia de competencia del Estado, pero con incidencia autonómica, correspondería la aprobación única al Congreso, previo informe de un Senado tipo Bundesrat.

73 L. AGUIAR DE LUQUE, "La participación del Senado en la función legislativa: una propuesta", cit., págs. 347 y 352.

74 L. LÓPEZ GUERRA, "La reforma del procedimiento legislativo del Senado”, cit., pág. 337.

75 J. J. SOlOZABAl ECHAVARRÍA, "Una Cámara de integración", El País, 2 de mayo de 2004.

76 L. AGUIAR DE LUQUE, «La participación del Senado en la función legislativa: una propuesta", cit., pág. 347. R. PUNSET, El Senado y las Comunidades Autónomas, cit., pág. 228; el procedimiento que propone para las reformas estatutarias supone la aprobación por el Senado en primer lugar y por mayoría absoluta, Comisión mixta paritaria de conciliación, cuyo texto sería asimismo votado por ambas asambleas y, en su defecto, por el Congreso por mayoría de tres quintos; por la misma mayoría, el Congreso podría formular un veto. Como señala este autor, la posición constitucional de la Cámara de representación territorial en la elaboración y modificación de los Estatutos de Autonomía resulta muy secundaria — a veces escandalosa — respecto de la que ocupa el Congreso de los Diputados, al igual que sucede en términos generales en el procedimiento de adopción de la legislación de directa incidencia autonómica ("El Senado en el procedimiento legislativo: una reforma imposible", cit., pág. 188). 
- la Ley Orgánica de financiación de las Comunidades Autónomas (157.3 $\mathrm{CE})^{77}$

- las leyes de distribución del Fondo de Compensación Interterritorial (158.2 CE).

En todo caso, parece necesario que las leyes que hayan de seguir en su tramitación un procedimiento especial estén determinadas por referencia a algún elemento objetivo que elimine conflictos en su calificación ${ }^{78}$. Por eso suele rechazarse la inclusión de las "leyes delimitadoras de las competencias de las Comunidades Autónomas "79, porque introduciría elementos de gran complejidad en un procedimiento ya complejo, con distintos tipos de leyes. Igualmente suele rechazarse incluir en esta categoría las leyes básicas ${ }^{80}$.

Otra propuesta en relación con otros tipos de leyes sería que el Pleno del Senado informara con carácter general y previo todo proyecto o proposición de cierto contenido autonómico que fuera a iniciar su andadura en el Congreso de los Diputados, manteniendo la labor de la Comisión General de las Comunidades Autónomas ${ }^{81}$.

c) Ámbito de la reforma constitucional del procedimiento legislativo.

En este punto, las propuestas reseñadas afectarían a los siguientes artículos de la Constitución:

- 87.2, si se modificara la Cámara a la que deben remitir las Comunidades Autónomas sus proposiciones de ley.

77 Una propuesta sobre la tramitación de este tipo de leyes, en R. PUNSET, El Senado y las Comunidades Autónomas, cit., págs. 230-231.

78 A favor de criterios objetivos de distinción y enumeración de los posibles, E. ALBERTí ROVIRA en el informe de trabajo "La reforma constitucional del Senado", en Ante el futuro del Senado, Instituto de Estudios Autonómicos, Barcelona, 1976, pág. 75; L. LÓPEZ GUERRA, «La reforma del procedimiento legislativo del Senado", cit., pág. 336. L. AGUIAR DE LUQUE ("La participación del Senado en la función legislativa: una propuesta", cit., pág. 353) atribuiría la calificación a la "Mesa de las Cortes Generales" en decisión irrecurrible, solventándose las dudas de constitucionalidad posteriormente, con ocasión de un proceso de control de inconstitucionalidad. M. GERPE LANDÍN ("La reforma del Senado", cit., pág. 787) se inclina por que la calificación de la naturaleza del proyecto o proposición de ley la realicen Comisiones mixtas paritarias.

79 L. AGUIAR DE LUQUE, ibidem, pág. 349; R. PUNSET, El Senado y las Comunidades Autónomas, cit., pág. 231, y "El Senado en el procedimiento legislativo: una reforma imposible", cit., pág. 195.

80 Las incluye a efectos de primera lectura del Senado, F. FERNÁNDEZ SEGADO («El Senado territorial, en El futuro del Estado autonómico, J. Rodríguez Arana y A. Díaz Otero, eds., Fundación Caixa Galicia, Santiago de Compostela, 1996, pág. 93, y "Reflexiones en torno a la reforma constitucional del Senado", Revista de las Cortes Generales, n. ${ }^{\circ} 37,1996$, pág. 281), como también los proyectos de ley que contengan una declaración de interés general legitimadora de la ley estatal (págs. 95 y 284, respectivamente); también J. RODRÍGUEZ ARANA ("Sobre la reforma del Senado. Notas acerca de su especialización funcional", Tapia, n. ${ }^{\circ} 88,1996$, págs. 18 y 20).

81 L. AGUIAR DE LUQUE, "La participación del Senado en la función legislativa: una propuesta", cit., pág. 35. 
- 88, si se desea convertir al Senado en Cámara de primera lectura respecto de algunos proyectos de ley.

- 89.2, al objeto, en su caso, de modificar la tramitación primera en el Congreso de las proposiciones de ley tomadas en consideración por el Senado.

- 90, en general, para rediseñar la posición del Senado en el procedimiento legislativo, en particular en cuanto a los plazos y la resolución de discrepancias con el Congreso.

Estos preceptos se circunscriben al capítulo dedicado por la Constitución a la elaboración de las leyes, aunque obviamente también podrían verse afectados, para establecer alguna especialidad procedimental, los artículos que contemplan las leyes reseñadas en el epígrafe anterior, así como el artículo 74.2, si se extendiera a otros supuestos la actuación de la Comisión mixta en ella prevista como mecanismo de conciliación.

\section{Otras funciones}

\section{a) Asuntos relacionados con la Unión Europea}

Ha suscitado una rara unanimidad en el debate abierto sobre la reforma constitucional la participación del Senado en los asuntos relacionados con la Unión Europea, o dicho de otro modo, la participación de las Comunidades Autónomas, a través del Senado, en la formación de la voluntad del Estado ante las Comunidades Europeas ${ }^{82}$, sin que esté claramente definida la forma de articular esta participación.

b) Cámara sede del debate político-territorial

Bajo esta rúbrica se encuadrarían cuestiones de naturaleza diversa, como sería centralizar en el Senado la cooperación entre Estado y Comunidades Autónomas ${ }^{83}$ y

82 J. LEGUINA VILLA ("La reforma del Senado y los hechos diferenciales", en A. PÉREZ CALVO (coord.) La participación de las Comunidades Autónomas en las decisiones del Estado, Tecnos, Madrid, 1997, pág. 216). En el mismo sentido, J. J. SOLOZÁBAL ECHAVARRÍA, "Una Cámara de integración”, cit. Véase al respecto G. JAÚREGUI, "La reforma del Senado y la participación de las Comunidades Autónomas en la Unión Europea", Revista Vasca de Administración Pública, n. ${ }^{\circ}$ 47-II, 1997, págs. 11 y ss.

83 F. FERNÁNDEZ SEGADO, "Reflexiones en torno a la reforma constitucional del Senado", Revista de las Cortes Generales, n. ${ }^{\circ} 37,1996$, pág. 289; E. AJA ("De los Gobiernos autonómicos", cit.: "Un Senado autonómico sería la instancia ideal para potenciar las relaciones eficaces entre todas las Comunidades Autónomas y con el Estado en las múltiples competencias compartidas que existen". No obstante, según E. ALBERTI, "Informe de trabajo", en Ante el futuro del Senado, cit., pág. 76, en el ámbito de la colaboración, el Senado estará fuertemente condicionado por su composición: en la medida en que las relaciones de colaboración vertical y horizontal se producen fundamentalmente en la esfera de los ejecutivos, las posibilidades de intervención del Senado crecerían en la medida en que su composición se encuentre más próxima a los mismos. 
hacer de esta Cámara el foro en que se debatieran cuestiones trascendentales para el Estado autonómico, como puede ser la financiación de las Comunidades Autónomas. Incluso se llega a hablar de una especialización "territorial" en materia de control del Gobierno.

La consulta al Consejo de Estado alude a esta temática como «las tareas que le correspondería desempeñar como espacio de conciliación y cooperación de las Comunidades Autónomas entre si y con el Estado":

c) Intervención de las Comunidades Autónomas en la integración de los altos órganos del Estado

Esta reivindicación de las Comunidades Autónomas quedaría resuelta con un Senado autonómico porque, para Aja, "cumpliría automáticamente esta función, reforzando la legitimidad de estas instituciones con más sensibilidad autonómica, ${ }^{84}$.

La consulta del Gobierno al Consejo de Estado al tratar de las funciones del Senado, se refiere a "las atribuciones relacionadas con otros órganos constitucionales".

\section{ASPECTOS RELEVANTES DEL FUNCIONAMIENTO DEL SENADO}

No por su menor importancia han quedado para el final (y sólo para ser enunciadas, porque por sí solas merecen un análisis individualizado) dos cuestiones claves del funcionamiento de un futuro Senado:

a) El eventual uso de las lenguas cooficiales en las Comunidades Autónomas, que el debate político viene reenviando en los últimos tiempos a ser resuelto en la Cámara Alta.

b) La forma de adoptar las decisiones en el seno de la nueva Cámara y el peso de las mismas en el sistema bicameral ${ }^{85}$, cuestiones condicionadas por las previas opciones sobre su composición y sus funciones. Como

84 E. AJA FERNÁNDEZ, "De los Gobiernos autonómicos", cit. En contra de una alteración de la intervención del Senado en relación con el nombramiento de órganos constitucionales, F. FERNÁNDEZ SEGADO, "Reflexiones en torno a la reforma constitucional del Senado", cit., pág. 291.

85 Sobre éste y otros aspectos de la "uniformidad y diferenciación en la posición de las Comunidades Autónomas en el Senado", puede verse E. ALBERTÍ, "Informe de trabajo”, cit., págs. 83-85. Obviamente, el hecho diferencial sólo puede tener acceso al Senado bien por la vía de la diferenciación en la composición, bien a través de las funciones (cauces de actuación específicos, incluso la posibilidad de vetar iniciativas), bien por ambas vías. En la obra colectiva Ante el futuro del Senado, cit., estudian la uniformidad y la diversidad en el Senado E. ARGULLOL MURGADAS, F. TOMÁS Y VALIENTE y J. M. CASTELL ARTECHE (págs. 507 y ss.). Véase también J. LEGUINA VILLA, "La reforma del Senado y los hechos diferenciales", cit., págs. 221-224. 
se ha dicho, aquí como en otros aspectos, las primeras decisiones políticas irán marcando el camino sobre el que se deba profundizar ${ }^{86}$.

\section{OBSERVACIÓN FINAL}

Parece inevitable, si se quiere llegar a hacer realidad la reforma constitucional del Senado, adoptar decisiones sobre las distintas cuestiones que se presentan. La composición y las funciones de un futuro Senado —así como algunas cuestiones trascendentes de su funcionamiento- van unidas, de tal manera que a medida que se inicie el proceso de decisión, el análisis deberá avanzarse en una u otra dirección.

En todo caso, no deben perderse de vista en ningún momento al afrontar cada cuestión "la función institucional" del Senado en el seno de las Cortes Generales y las "consecuencias sistemáticas" sobre el conjunto de la estructura constitucional que el modelo de configuración del Senado comportaría, interrogantes que figuran en último lugar en la consulta al Consejo de Estado, pero que son de la mayor trascendencia por sus efectos sobre el entramado constitucional.

ABSTRACT. The reform of the Senate, the Upper House of the Cortes Generales, has long been a major topic in Spanish political and academic debates. At a time when the Senate's reform is apparently under way, this paper studies all the issues involved, as well as the options open to the reformers in relation to the Senate's composition and powers, in view of the experience in similar Chambers in other countries and in view of the available literature. Regarding its composition, the paper argues that Senators might either be chosen in regional districts, or by the Parliaments of the Autonomous Communities, and considers unsuitable the Bundesrat model. In relation to its functions, the reformed Senate should bring its legislative powers closer to the Congress', as well as emphasize its territorial character. In any case, all proposed reforms must take into account their consequences on the institutional framework set up by the 1978 Constitution.

86 Una primera y original propuesta de dos sistemas distintos de votación, in capita y comunitario, en el que los representantes de cada Comunidad Autónoma tendrían un solo voto, en R. BLANCO VALDÉS ("La reforma del Senado", cit., pág. 45). El voto comunitario afectaría a la reforma de la Constitución, la financiación de las Comunidades Autónomas, la aplicación del artículo 155 $\mathrm{CE}$, la autorización de tratados internacionales y de acuerdos de cooperación entre Comunidades Autónomas y la distribución del Fondo de Compensación Interterritorial. En estos casos, el Senado dispondría de veto no superable por el Congreso de los Diputados. 